\title{
EJERCITAR EL KAMISH.
}

\section{Etnografías acústicas del islam y desafíos de lo sonoro en la construcción de subjetividades}

\author{
Juan Carlos Castrillón Vallejo \\ ANTROPÓLOGO, INVESTIGADOR INDEPENDIENTE \\ juancarloscastrillon8@yahoo.com
}

\begin{abstract}
Resumen
[ste artículo analiza cómo la religión, mediante la música, se inscribe de diferentes [maneras en los individuos por medio de prácticas y discursos específicos. En primera instancia propone una argumentación que explora el pensamiento sobre lo sonoro y sus estrategias en la producción de subjetividades, para aplicarla al contexto de la música sagrada del islam en general, y a la enseñanza de la flauta ney en Estambul en particular. En segunda instancia, muestra la dupla oratoria y enseñanza musical presente en la interacción entre maestros y estudiantes, y la propone como piedra de toque de la comprensión de lo sonoro en la producción de subjetividades en el islam espiritual. Finalmente, el texto presenta y discute los marcos de experiencia donde se inscriben los discursos provenientes de la mística musulmana y donde las disciplinas espirituales y sus practicantes definen su eficacia.

PAlabras Clave: antropologías del islam, pensamiento musical, ney, sufismo.
\end{abstract}

\section{Training Kamish.}

\section{Acoustic Ethnographies of Islam and Challenges of Sound in the Construction of Subjectivities}

\begin{abstract}
This paper discusses how religion through music is inscribed in different ways on people's practices and specific speeches. First, it suggests an argument that explores sound thinking and its strategies related to the production of subjectivities, so that to apply it to the context of sacred music of Islam in general and particularly to the Ney's flute teaching in Istanbul. Second, it shows the duo oratory and music teaching expressed by way of the interaction between students and teachers, which are suggested as a touchstone for the understanding of sound throughout the production of subjectivities in the spiritual Islam. Finally, the paper shows and discusses the frames of experience where the speeches coming from the Muslim mysticism are inscribed and where spiritual disciplines and their practitioners define their effectiveness.
\end{abstract}

KEY WORDS: anthropologies of Islam, musical thought, ney, Sufism.

\section{Revista Colombiana de Antropología}

Volumen 48 (2), julio-diciembre 2OI2, pp. II5-I38 
Ejercitar el kamish. Etnografías acústicas del islam y desafíos de lo sonoro en la construcción de subjetividades

\section{INTRODUCCIÓN: NO OÍMOS, APRENDEMOS A ESCUCHAR ${ }^{1}$}

a licitud de la escucha de los creyentes orientada hacia la música, en el islam, es una discusión que ha tenido diferentes -tonos a través de la historia: ha habido un rigor de prohibición máximo, cuando se ha restringido su escucha, su enseñanza y su circulación en medios radiales. También un nivel moderado,

1 Agradecimientos a los evaluadores anónimos y a la editora de la Revista Colombiana de Antropología por sus revisiones de este texto.

2 A lo largo del texto se escribirán en mayúscula aquellos términos provenientes del islam traducidos del idioma turco para diferenciarlos de los que son usados en las ciencias sociales y de los que son referidos fuera de un ámbito específicamente religioso. cuando la música ha estado más o menos controlada o ha sido permitida por haber sido despojada de cualquier poder que pudiera impactar de manera decisiva en sus oyentes. Pero en la historia de las sociedades que han vivido y cultivado el islam, también ha

habido un nivel máximo de fidelidad sonora, en el que la música ha llegado a presentarse como la suma posibilidad, por cuyo medio el discurso divino se hace audible a sus oyentes (Puerta 1997, 105; Shehadi 1995, 94).

En las sociedades musulmanas estas discusiones respecto a la licitud de la música se han multiplicado y han dejado en evidencia los dominios que componen el ejercicio de la subjetividad, las instituciones que cuidan las prácticas y las representaciones garantes de su sentido. El presente artículo busca mostrar etnográficamente que en la espiritualidad musulmana la práctica musical es una forma de oración, es como es en verdad. En cambio, en el interior de la Norma Religiosa del Islam² o shariat querer agregarle al islam "algo más" se considera como una innovación, algo que hay que evadir, censurar o prohibir para evitar su deformación. De allí que se puedan esperar afirmaciones tales como que en el islam la música está prohibida o que las recitaciones del Corán no pueden ser consideradas cantos (Castellanos 2010, 36). Este tipo de aseveraciones, más que definir el islam, muestran la tensión presente en los dominios de la subjetividad, en el aprendizaje de la música sagrada y en la relación entre poder y verdad en el islam.

En palabras de Pierre Bourdieu, este tipo de tensión tiene relación y pone en evidencia el campo (1990, 229-230) en el que estudiantes y maestros están implicados. Campo donde están en 
discusión las formas de postulación y los estatutos de reconocimiento que les permiten a ciertas personas ser presentadas como el Maestro de Ney de su tiempo (Kutb-i Nayi). También está en discusión la efectividad de la enseñanza musical como proceso de transformación subjetiva, como modo de intimar con Allah, con la Verdad, y no solo la cuestión de si la música es lícita o no. Como mostraré, la enseñanza y la práctica musical en la espiritualidad musulmana tienen más ingredientes heredados de una larga tradición esotérica que de una discusión teológica interesada en zanjar o competir por las normas de la religiosidad.

Los juegos de verdad presentes en esta tensión oscilan entre las representaciones y las prácticas promovidas por profesores de música en sus estudiantes por medio de los "métodos de disciplinación sonora" (Moreno 2004, 2). Estos han sido definidos como el conjunto de "presupuestos cognitivos que condicionan variadas construcciones de la escucha, de la audición, de la percepción y de la comprensión de lo sonoro por y para varios sujetos (que corresponden de manera amplia, aunque de ninguna manera exclusiva, a los 'oyentes ideales' de las teorías) y del pensamiento musical de las épocas históricas"3 (Moreno 2004, 2); 3 Traducción del autor.

muy distantes de ser presentados como el repertorio de un saber/ hacer meramente técnico y de carácter instrumental, despojado de cualquier densidad psicológica e histórica. A diferencia de aquellos estudios que enfatizan el carácter identitario, tradicional, clásico o formal de la pedagogía musical y de las técnicas de ejecución e interpretación propiamente dichas, este artículo se concentra en las representaciones con las cuales se curva y se establece ese tiempo fisiológico del oyente, como acostumbraba decir Claude Levi-Strauss (1996, 26), o aquellas epistemologías de lo sonoro de las que habla Jairo Moreno $(2004,2)$. La escucha es una construcción específica, derivada y deudora de un conjunto de tecnologías de índole diversa, implicada directamente en tensiones de diferente naturaleza, y no únicamente una facultad perceptiva que funciona sin necesidad de un aprendizaje posterior. Esta antropología de lo sonoro interroga los niveles objetivos en los que la escucha impacta la construcción de subjetividades, y muestra los enlaces entre la espiritualidad musulmana y la enseñanza de la música, y la relación entre la interacción maestros/ estudiantes y la continuidad de las representaciones sobre el uso litúrgico de objetos sonoros. 
Ejercitar el kamish. Etnografías acústicas del islam y desafíos de lo sonoro en la construcción de subjetividades

¿Qué le concede entonces esa cualidad a la escucha de cada oyente? ¿Cuáles son las prácticas y los discursos entre los cuales las personas entrenan cualitativamente su escucha, de tal manera que al oír escuchan algo en particular? ¿Tienen esas prácticas algún impacto en la producción de las subjetividades y en sus marcos de experiencia? El planteamiento central de este texto es que este disciplinamiento sonoro articula, organiza representaciones y contenidos empíricos de tal forma que moldea la escucha y la pone en relación con otros ámbitos de la experiencia humana, como la religión y la experiencia mística. Desconocer los ejes de este disciplinamiento nos hace sordos a las motivaciones e intencionalidades que animan a los intérpretes a emparentarse con sus maestros. Nos hace sordos a las contiendas por el sentido de lo sonoro, y a todas las acústicas (otrora visiones del mundo) que también componen la realidad de las sociedades humanas. Y finalmente, nos aleja de la comprensión de procesos generadores de subjetividad propiciados por lo sonoro en el islam. Preguntarnos por las maneras en que se ejerce este disciplinamiento implica atender a todas aquellas "prácticas, representaciones, cartografías y curvaturas" (Castro, Castro y Castro 2008, 296) que sitúan a los oyentes e intérpretes en marcos de experiencia específicos. De tal manera que nosotros, al oírlos, podamos escuchar de ese algo en particular que ellos oyen aquello que estamos interesados en informar, discutir y analizar, en este caso la

4 Kamish: nombre de la planta usada en la construcción de dos objetos, la flauta ney, empleada con frecuencia en la música religiosa de algunos países del islam, y el cálamo, instrumento predilecto de los calígrafos musulmanes para trazar el Corán y otros textos afines. relación entre religión y cultura. El artículo no pretende esencializar el ejercicio del kamish ${ }^{4}$ para salvarlo de los discursos políticos nacionalistas turcos ni de otros órdenes de ese tipo. Lo que pretende es exponer las fibras que vibran cuando se escucha la flauta ney, un instrumento capaz de hacer vibrar las alusiones a la experiencia mística en el islam. Fibras aquí presentadas como ámbitos de la experiencia humana en resonancia: la religión, la experiencia mística y la oratoria musical.

En el caso particular de los métodos de enseñanza de la flauta ney en Turquía, este texto no se apresura a presentarlos como patrones culturales, ni como rasgos de la "cultura del ney". Este texto evita referirse a la práctica musical como algún tipo de símbolo común y presente en todas las culturas, con diferencias particulares. Centrar el interés en las prácticas - y sobre todo en 
aquellas relacionadas con el aprendizaje- obedece a la relevancia que tienen para la eficacia simbólica, garante de la relación entre música y experiencia mística en el islam. En el presente texto las prácticas son entendidas como un conjunto de mecanismos que ponen en relación a los sujetos con sus objetos/sujetos de interés, capaces de actualizar y moldear los modos de ser de las personas a partir de actividades específicas. Por eso aludo a un proceso de disciplinamiento sonoro, y no a una simple interiorización de un acervo de significados culturales universales. En este proceso, identificado a partir de cuatro fases de trabajo de campo efectuadas en Turquía entre los años 2005 y 2012, existe una constante lucha por las representaciones de lo lícito, lo santo y lo sublime del sonido, librada entre estudiantes y profesores de ney, quienes además consideran su actividad dotada de trascendencia y densidad religiosa, e inscrita en el proyecto esotérico de la Revelación Coránica. Un proyecto presentado aquí como el ejercicio del kamish: una modalidad de didáctica mediante la cual Allah, a partir del uso litúrgico de dos objetos elaborados de una misma planta llamada kamish, les enseña a los seres humanos lo que de Él ignoran.

\section{Topologías Y ACústicas de LA Revelación}

a oración, en el islam, es conocida como salat. En ella tienen su forma prescripciones y periodicidades establecidas, dadas Len el interior de la shariat, y entre las cuales no se incluye "la música”. Por lo tanto, querer agregar algo más a la oración no es coherente ni en el islam ni en este texto. Existen, sin embargo, diferentes tipos de oración además del salat, como las plegarias para realizar acciones cotidianas como comer, bañarse, emprender un viaje, etc., conocidas en Turquía como súplicas o dua. Pero más importante es que hay grados de entrega a las actividades cotidianas, en las cuales divinidad, estética y expresión suenan, colorean y danzan (Bakhtiar 1976, 98; Corbin 2005, 131; Puerta 1997, 750). Los sujetos presencian y viven en sus acciones estos grados: ser el oído por el cual el profeta Muhammad oye, ser la visión por la cual él ve, ser la mano con la cual él toma y ser el pie con el cual avanza. La insistencia de este texto en acentuar 
la dupla música-oración busca señalar las formas en las cuales operan los procesos de disciplinación sonora en la espiritualidad musulmana. Maneras de las cuales estos músicos se sirven para transformarse gracias al acompañamiento de sus maestros, hasta llegar a ser el oído por el cual el Profeta oye, o la mano por la cual el Profeta toma.

Sin embargo, el sentido de cierta práctica musical en algunas regiones del espacio/tiempo musulmán, vivida como eco clarividente y exaltador de la unicidad divina, no compite en ningún momento con las cinco prosternaciones diarias y obligatorias en dirección a la $K a a b a^{5}$, en las que insiste la Norma Religiosa

5 Lugar de peregrinaje ubicado en la Meca. Los musulmanes de todos los países se orientan hacia allí cuando realizan sus cinco plegarias diarias. Visitar este lugar al menos una vez en la vida es uno de los pilares del islam. del islam. No se pretende aquí erigir la práctica musical como un tipo de oración alternativa. Lo que se pretende es comunicarle a un público más amplio que la oración formal, el salat, no es la única práctica en el islam en la que los creyentes viven la revelación, esa comunicación entre el Dios de las religiones abrahámicas (cristianismo, judaísmo e islam) y sus siervos, a partir de ángeles, profetas, santos, santas y mensajeros. La Revelación Coránica también se vive en los lugares donde ocurren las visiones de los profetas y de los místicos, los actos simbólicos de los ritos de iniciación, las liturgias en general con sus símbolos, y en las demás composiciones de lugar que proponen los diversos métodos de oración, cuya localización no se deduce a partir de datos geográficos (Corbin 1996, 24). La Norma Religiosa del islam ha considerado el salat como el lugar único donde el creyente tiene un fuera-de-sí, un momentum de intimidad con Allah. Sin embargo, para los fuqara, sufíes o sufis y para los derviches — quienes viven el islam como una religión profética e iniciática, como una religión en la cual hay un mensaje que la divinidad revela y para cuya interpretación se precisa de una inmersión guiada, personal e íntima, salvaguardada por un parentesco que sus iniciadores tienen con la familia espiritual del profeta Muhammad - los lugares de oración, encuentro y cercanía con Allah son muchos y muy variados. 


\title{
Enseñanza musical y sufismo
}

\begin{abstract}
El sufismo no es otra cosa que la mística islámica, lo que significa que es la corriente central más potente de esa marea que constituye la Revelación del Islam [...].

Por lo que se refiere a los miles de hombres y mujeres que, en el mundo occidental moderno, pretenden ser "sufies" sosteniendo que el sufismo es independiente de toda religión específica y que ha existido desde siempre, sin saberlo lo están reduciendo.
\end{abstract}

Lings, ¿Qué es el sufismo?

a pedagogía musical de algunas prácticas religiosas del islam es un aspecto derivado de la revelación: proyecto en el cual Lestán incluidos el islam, el cristianismo y el judaísmo por haber recibido de la divinidad una palabra dada y por haber hecho un pacto de cuidarla y cultivarla, tal y como se ha venido exponiendo. Estas tres experiencias y visiones del mundo hacen común a diferentes grupos de individuos un conjunto de textos revelados por la misma fuente. Estos grupos se asumen emparentados espiritualmente a la descendencia abrahámica. La espiritualidad musulmana, y en especial el sufismo, se conciben a sí mismos como una forma de supraparentesco nombrado en términos y en acontecimientos imaginales, espirituales, y no meramente simbólicos, alegóricos o arqueológicos, que comparten quienes están relacionados entre sí. La pedagogía musical de algunas prácticas religiosas del islam, por consiguiente, también se alimenta de esta fuente, dado que de ella obtiene su validez y eficacia.

En nuestro ámbito académico, la música en el islam se ha presentado generalmente como algo velado, vedado y poco especializado. Por fortuna, el discernimiento antropológico ha enseñado que la música se presenta como un objeto inserto en múltiples acontecimientos sociales. Sobre este aspecto Jean During ha dicho que "la música fue adoptada por las cofradías sufíes a principios del siglo Ix, como soporte de meditación, como manera de llegar a estados de gracia o de éxtasis, o simplemente para alimentar el alma” $(1996,197)$. Sin embargo, lo que este texto discute no es que la música propicie o no estados de gracia o de éxtasis; sino que la experiencia de la música en el sufismo, aprender a interpretar tal o cual instrumento, cantar, son en sí mismos actos a través de los cuales el intérprete vuelve a situarse en una experiencia iluminativa, en la que su audición y su gesto musical se sitúan "más acá” de 
Ejercitar el kamish. Etnografías acústicas del islam y desafíos de lo sonoro en la construcción de subjetividades

la normatividad melódica, armónica y rítmica de los sonidos: una experiencia de la música en la que la subjetividad del intérprete se prepara para entrar en flujo con los sentidos, y así su práctica musical alcanza su máxima sonoridad y trascendencia. Para que dichas prácticas se presenten como procesos de subjetivación orientados hacia la transformación de sí mismo en relación con la divinidad, deben proveer una materialidad que movilice, actualice o propicie un encuentro entre diferencias, y también deben ser matriz de un conjunto organizado de discursos específicos. Una materialidad y sustrato donde se encuentren la Palabra Revelada en la oración, las Cualidades o Nombres Divinos en la práctica musical y las personas que las viven gracias a sus disposiciones corporales y a su entrega al aprendizaje de la música. Esa materialidad es la audición. La escucha puesta en marcha gracias a un trozo de caña (Arundo donax L.) llamado ney en este caso. Pero no se trata de la escucha en un sentido pasivo receptivo, a través de la cual, como señaló Lévi-Strauss, "cada oyente le da sentido a lo escuchado a partir de su pool de cargas semánticas estructuradas o propias" $(2000,586)$, sino de la escucha en un sentido activo y creativo, en el que cada oyente según su condición —esa que le permite ser el oído por el cual el Profeta oye, la mano mediante la cual Él toma y lanza - toma parte en asuntos éticos y epistemológicos: contiendas por el conjunto de estrategias que como mínimo validan o anulan la audición como eje de conocimiento, interpretación y comprensión. La experiencia de orar con o sin instrumentos sonoros no implica de antemano enajenación o iluminación. Más bien se insiste aquí en enfocar la atención en estos momentos-actos, y en considerarlos como prácticas que le permiten a la presencia humana aprender y ejercitar dichos sentimientos y actualizar dichas emociones, así como lo anota Foucault cuando dice que "una mentalidad se forma a través de sus prácticas" $(1978,618)$, y no solo "se ajusta en ellas", como

6 El tratamiento que le dio Mauss a la oración trasladó el antagonismo entre sociedad e individuo a los asuntos religiosos, atenuó la presencia y la voluntad del individuo en acontecimientos de cara a lo sagrado y resaltó el carácter esencialmente social del fenómeno (Mauss 1970, 1 15-1 16). Su análisis dejó por explorar aquello para lo cual es necesaria, requerida o indispensable la oración para los individuos. Este artículo discute dicho análisis centrado en el carácter lo planteaba Mauss respecto a la oración $(1970,116)^{6}$. En síntesis, presentar los contextos y las condiciones de posibilidad en que estas prácticas se articulan a métodos de disciplinación sonora dentro de la experiencia de la subjetividad en el islam. 


\title{
El lamento del ney: una tradición otomana vigente en Turquía
}

\begin{abstract}
El ney tiene espiritualidad. Mevlana decía: "El ney y el ser humano se parecen".

Los estudiantes aprenden humanidad, respeto, cultivación de sí mismos y desarrollan su alma en sus clases. También aprenden sobre amor e islam simultáneamente. Esto no lo aprende el estudiante por cuenta propia.

Los maestros estimulan, advierten y corrigen a sus estudiantes. Todo esto no es solo sobre ney, es sobre nuestro arte. La forma de enseñanza de nuestro arte hace de los estudiantes fem-i Muhsin, "bocas bellas". El ney es solamente una herramienta para ser una buena persona.
\end{abstract}

Entrevista con Ahmed Shajín ${ }^{8}$

a forma como algunos profesores de Estambul asumen su tra-
bajo sugiere una enseñanza musical implicada con la ascesis
individual en el marco de la espiritualidad musulmana. Dichos
métodos de entrenamiento musical se abren espacio y se actualizan
en medio de circunstancias contemporáneas, como la contienda
por la construcción de un pasado nacional turco, en oposición a
las formas socioculturales y espaciotemporales otomanas. Para
comprender esta implicación entre
Quienes apenas se acercan a las prácticas culturales otomanas en la Turquía actual pueden verse atrapados en un litigio de tiempo 
Ejercitar el kamish. Etnografías acústicas del islam y desafíos de lo sonoro en la construcción de subjetividades

y espacio cuando se trata de investigar la actualidad de estas prácticas. Litigio de tiempo, pues el proyecto de Estado nacional turco efectuó un corte con todo ente organizador y orientador de la vida pública anterior a él. Desde los años veinte del siglo pasado, el Estado nacional promovió un olvido histórico de aquellos órdenes de experiencia articulados en torno al Imperio otomano, las instituciones religiosas y las formas de diferencia étnica y lingüística. Desde los años ochenta el Estado nacional turco puso en marcha estrategias de articulación y visibilización, más que de inclusión y reconocimiento, por medio de la patrimonialización y el turismo. Y un litigio de espacio, debido a la producción de un sistema nacional de espacios nacionales o laicos a partir de la desentronización, el desplazamiento y la yuxtaposición de lugares antes primordiales para el ejercicio, la formación y el cultivo de dichas prácticas, ahora lugares memorables, significativos y supervivientes de un pasado arquitectónico e histórico.

En este apartado enfatizo en que dicha práctica musical no es producida, no aparece ante nosotros, investigadores, desde la discusión legal de si es prohibida o no, si es sagrada o no, si es secularizada o no. Sino que, en el caso de la música asociada a prácticas de oración del islam, es producida desde un lugar que la revelación le concede, y no desde las formas de legitimidad que el Estado o la investigación académica puedan o quieran - o no- otorgarle. Desde allí deben hacerse las preguntas e interpretarse las contiendas que impactan las relaciones sociales e íntimas entre maestros y estudiantes del ney en Estambul. Si las formas de plegaria musical, como la danza circular (sema) y el recuerdo de Dios (zikr), en las que se usa la flauta ney, poseen rasgos externos amplificados por los instrumentos, los idiomas y por las mismas prácticas en cuestión, no son estos los que les confieren su sentido, su condición de posibilidad y permanencia. Emparentar y relacionar estos rasgos, hablar desde ellos, es distinto a tratar los polos que orientan las prácticas aquí referenciadas y ampliadas. Es distinto investigar los ejes que las hacen converger hacia sus metas y finalidades originarias, emergentes del ámbito tradicional, a pesar de las dificultades que encuentren en un contexto histórico nacional como el turco. Evitar entrar en una contienda por la autenticidad de estas prácticas musicales en un contexto como el turco implica centrar la atención en las formas constitutivas de un pensamiento y una praxis de lo sonoro, a partir de sus alusiones provenientes de la espiritualidad musulmana. 
No con el fin de alcanzar cierta "ubicación estratégica”, propia de un orientalismo que naturaliza discursos provenientes de las realidades ajenas que estudia y que "representa hablando en su nombre", como alertaba Edward Said (2002, 49), sino con el fin de hacer audibles a los interlocutores los contextos y las relaciones a la hora de pensar lo sonoro en un ámbito religioso, como el musulmán.

¿Cómo participan los estudiantes de ney de ese proyecto de didáctica en el que Allah, a partir del uso litúrgico de dos objetos elaborados con una misma planta llamada kamish, les enseña a los seres humanos lo que de Él ignoran? Los estudiantes participan por medio de las diferentes formas corporales y musicales en las que se ha interpretado el Corán y demás discursos constitutivos de la espiritualidad musulmana. Habitualmente, nuestras ciencias sociales han conceptualizado la experiencia biográfica de sujetos insertos en prácticas y discursos e instituciones específicas en términos de subjetividad, y han presentado los ámbitos vividos, padecidos, imaginados y expresados por dichos sujetos como los dispositivos inherentes a su producción (Castro, Castro y Castro 2008, 518). Ahora bien, estos sujetos, en tanto músicos - maestros y estudiantes de flauta Ney- participan de una experiencia vivida, padecida, imaginada, expresada en representaciones y prácticas que ellos reconocen como el sonido, mi sonido. Una experiencia posible que emerge de la relación concreta con otro cuerpo: el instrumento. Analizada la práctica musical de esta manera, ni el talante del sonido con su ubicación acústica en un registro determinado, ni la efectividad de los sistemas de notación musical constituyen el propósito del entrenamiento, el ejercicio, la práctica y la disposición respecto a la música. Si continuase siendo de esta manera, la disposición, el entrenamiento y la relación entre los dos cuerpos, músico e instrumento, devendrían únicamente en desciframiento y lectura musical, y no en tecnología de sí (Foucault 1990, 48), en plegaria musical (Jáuregui 1997, 79) o en experiencia creativa (Bakhtiar 1976, 6). Y mucho menos sucederían como hermenéutica de símbolos, tal y como los han vivido los espirituales del islam por siglos, del modo como se lo proponen los maestros de ney en Turquía: una ciencia del Hombre en la que son discutidos, fundamentados y habituados modos diversos de la presencia humana a partir de una relación trialéctica entre el músico, el sonido y el instrumento. A los profesores de música que así 
Ejercitar el kamish. Etnografías acústicas del islam y desafíos de lo sonoro en la construcción de subjetividades

consideran su oficio — como sugiere el relato inicial de Ahmed Shajín- les será familiar usar en sus clases, métodos y sesiones de enseñanza diversos ejercicios para expandir, guiar, emular y comparar las impresiones corporales de sus estudiantes, junto a las demás consideraciones de orden moral y estético provenientes del islam y amplificadas por lo sonoro.

¿De cuando acá tanto esfuerzo y atención a una normatividad melódica, armónica y rítmica formulada/expresada en la combinación de sonidos, capaz de guiar la experiencia del músico hacia la lectura —-melódica y rítmica - del sonido? ¿Dónde queda esa experiencia de lo melódico, lo armónico, lo rítmico, lo recurrente, lo disonante, lo profundo, lo conjunto, lo ligero, lo sutil, lo brioso, lo generoso, lo continuo, lo lento y otras tantas cualidades - que en el islam se conocen como cualidades divinas - que pueden ser pensadas, presenciadas, experimentadas, comparadas y estudiadas gracias a la experiencia envolvente de la práctica musical? Con todo crédito puede Foucault guiar la experiencia del lenguaje hacia la tierra dual y diferente de la crítica y el discurso; y puede meditarse y tener lugar la pregunta por la música como representación en el ámbito musicológico de Estambul, allí mismo donde — según la historia de la caligrafía islámica- el Corán conoció el trazo redondeado y suave, luego de haberse acostumbrado por siglos a un trazado rígido y anguloso.

\section{Sublime Corán, TrAdiciones sufíes y FLAUTA NEY}

「l islamólogo Henry Corbin ${ }^{9}$ subrayó en uno de sus últimos

-artículos que el sentido de la música sacra en Occidente no ha - seguido el mismo devenir que esta tuvo en los países del islam. En estos últimos países la música entró a ser parte indisoluble de la experiencia mística e incluso contribuyó al ordenamiento

9 A pesar de no ser antropólogo, este autor abrió una posibilidad para estudiar el comportamiento, las prácticas y su relación con los discursos de las tradiciones místicas y esotéricas, facultando a la etnografía y la fenomenología como métodos indispensables para los estudios de las religiones monoteístas. de su sentido. Para comentar ese ordenamiento de la experiencia mística y su relación con la música, hizo un análisis interpretativo de estas primeras líneas del Masnavi: 
Escucha la historia que cuenta el ney, la de las separaciones cuyo lamento exhala. Desde que fui cortada del cañaveral, mi queja ha hecho lamentarse a hombres y mujeres. El que es abandonado lejos de su fuente original, aspira volver al tiempo de su unión. Mi secreto no está lejos de mi queja, pero la luz está ausente al ojo y al oído. El cuerpo no está velado al alma, el alma no está velada al cuerpo; sin embargo, a nadie le está permitido ver el alma. (Corbin 2005, 133)

De estas líneas Corbin dedujo que: a) el alma solo se puede presentir por la queja de la flauta mística cortada y separada del origen, la Tierra de Luz; b) la historia del exilio y el retorno es la obsesión de la mística persa; y c) esa historia, tanto como el alma, es susceptible de contarse, vivirse y verse, en la medida en que la audición musical llegue a hacernos "súbitamente clarividentes" (2005, 132-133). Hasta aquí, este autor no ha hecho sino esbozar para nosotros los tres ejes fundamentales presentados en este texto: el uso litúrgico de la flauta ney, un acontecimiento espiritual propio del esoterismo musulmán y un tipo de escucha capaz de alcanzar el sentido de dicho acontecimiento. Pero claro, las referencias a la experiencia musical de la mística musulmana no terminan en "la historia del exilio y el retorno" estudiada por Henry Corbin $(2005,133)$. ¿En qué otros ciclos de esa historia espiritual están por esencia los místicos "en el deber de cantar para decir" (134)?

\section{La escucha del profeta Muhammad}

Judíos, cristianos y musulmanes tienen en común el poseer un Libro Sagrado (la Torá, la Biblia, el Corán), regla de vida en este $\checkmark$ mundo y guía en el otro. Para estas tres comunidades los hechos y acontecimientos - en sentido estricto - se basan, se viven y se presentan como búsquedas, comprensiones y exploraciones del sentido verdadero contenido previamente en el Libro. Este tipo de exploraciones no se hace de manera teórica, sino que implica un camino, una vía por entre la religión revelada. Esa vía, en el islam, ha sido llamada tariqat, la tradición esotérica de la espiritualidad musulmana, conocida habitualmente con el término sufismo. Como hemos referido antes, este camino se propone la transformación del comportamiento y del discernimiento en el ser humano a partir del modelo propuesto por el profeta Muhammad. Para captar esa relación entre comportamiento y 
Ejercitar el kamish. Etnografías acústicas del islam y desafíos de lo sonoro en la construcción de subjetividades

comprensión presente en las Comunidades del Libro e identificar la relevancia de la práctica musical en este contexto, es preciso acudir a una de las formas mediante las cuales el islam describe y rige el comportamiento.

Además del Corán, los creyentes musulmanes — sufíes incluidos- hacen de los hadices uno de sus mejores manuales de comportamiento para la vida pública

10 Los hadices son dichos o relatos compilados después de la muerte del profeta Muhammad e informan sobre la manera como vivía.

11 Yerno del profeta Muhammad, esposo de su hija Fátima, padre del imam Hasan y el imam Husein. e interior ${ }^{10}$. Entre muchos de estos, los espirituales encargados de velar la relación entre música y mística musulmana destacan y meditan sobre el siguiente:

El Mensajero de Dios (paz y bendiciones sobre él) dijo: Dios dijo: Quien muestra enemistad hacia un amigo mío, le declararé la guerra. No se acerca mi siervo a mí con algo más querido para mí que lo que le he ordenado, y mi siervo continúa acercándose hacia mí con obras voluntarias hasta que yo lo amo, y una vez lo he amado, seré su oído con el que escucha, su vista con la que ve, su mano con la que toma, su pierna con la que anda; si me pide algo se lo concederé, y si me pide refugio, se lo daré. (An-Nawawi 2006, 23)

Puesto que no existen diferencias de castas entre los musulmanes, sino estos niveles de comportamiento y comprensión — de entrega al amor de Allah-, cada fiel puede postrarse y acceder, según sus méritos, al rostro del Profeta y al verdadero sentido del Libro Revelado: a la Presencia de Allah. ¿Cómo puede el intérprete de ney llegar a tener un oído de tal magnitud que le permita acercarse a esa escucha interior del profeta Muhammad, considerado como el prototipo de ser humano perfecto y el oyente ideal por excelencia? Cito en extenso una tradición guardada y transmitida por Yelaluddin Rumi, gracias a la cual entendemos el sentido del vínculo entre maestros y estudiantes y la dimensión de la práctica musical en la espiritualidad musulmana aquí analizada:

Se dice que un día el Profeta (Muhammad) recitaba en privado a Alí11 los secretos y misterios de la "Hermandad de la Sinceridad" (que parecen ser los "iniciados ocultos" del mundo derviche musulmán), advirtiéndole que no los divulgase a nadie que no estuviera iniciado, para que no fuesen traicionados; también, le amonestaba a obedecer la ley de la sumisión rígida. Durante cuarenta días, Alí guardó el secreto para sí en su corazón y lo llevó con él hasta que su corazón enfermó. Como una mujer embarazada, su abdomen se hinchó con esa carga, de forma que ya no podía respirar libremente. 
Así pues, desapareció en plena naturaleza salvaje y encontró por azar un pozo. Se detuvo, introdujo su cabeza todo lo que pudo en el pozo y entonces confió uno por uno aquellos misterios en las entrañas de la tierra. Con el exceso de excitación, su boca se lleno de espuma, que también escupió en el agua del pozo, hasta que se liberó totalmente y se sintió aliviado. Cuando pasaron algunos días, pudo observarse que una caña solitaria crecía en ese pozo. Esta creció con firmeza hacia arriba hasta que, finalmente, un joven cuyo corazón fue milagrosamente iluminado se dio cuenta de esa planta que crecía, la cortó, hizo agujeros en ella y empezó a tocar aires similares a los tocados por los derviches amantes de Dios, mientras pastoreaba su ganado por los alrededores. Poco a poco, las diversas tribus de árabes del desierto oyeron hablar de la música del pastor, y su fama se extendió. Los camellos y el ganado de toda la región se reunían a su alrededor mientras él tocaba, dejando de pastar para poder escuchar. De todas las regiones del norte y del sur, los nómadas acudían en tropel a oír sus melodías, entraban en éxtasis llenos de deleite, llorando de alegría y placer y cayendo en trances de agradecimiento. Finalmente, el rumor llegó a los oídos del Profeta que dio órdenes para que el flautista fuera llevado ante él. Cuando empezó a tocar en la Presencia Sagrada, todos los discípulos santos del Mensajero de Dios se conmovieron hasta las lágrimas y entraron en trance, estallando en gritos y exclamaciones de pura bienaventuranza, y perdiendo toda conciencia. El Profeta declaró que las notas del pastor eran la interpretación de los misterios sagrados que él había confiado en privado a Alí. (Eflâkî 1976, 131 y ss.)

En este texto encontramos otro ciclo de la historia espiritual del islam, en el que puede analizarse la audición mística como una prerrogativa hereditaria, prodigada y actualizada entre quienes viven y cuidan el sufismo. Este relato hace parte de las representaciones que la espiritualidad musulmana considera fundantes de la sacralidad de lo sonoro. No son el sonido del ney, hoy convertido en un objeto sonoro de la familia de los aerófonos, ni el instrumento predilecto de una histórica y particular "cultura sufí” lo que regocija a las comunidades de creyentes, profesores y estudiantes del ney que alumbran sus vidas bajo la luz del Corán. No. Los instrumentos musicales en sí mismos no suenan. Claude Lévi-Strauss, en su "Obertura”, desarrolla dos aspectos claves que muestran el estado actual de nuestra discusión: a) "la comparación entre mitología y música, en tanto ambas suprimen el tiempo y trascienden el plano del lenguaje articulado" (1996, 25); y b) "las relaciones entre emisor-receptor que ocurren en el tiempo fisiológico del oyente, donde la intención del compositor se 
Ejercitar el kamish. Etnografías acústicas del islam y desafíos de lo sonoro en la construcción de subjetividades

actualiza —como la del mito- a través del oyente y por él” (26), tal y como se ejemplifica en la actitud del profeta Muhammad frente al sonido de las notas musicales del pastor. "Esa relación entre emisor-receptor donde la música se vive en nosotros, y nos escuchamos a través de ella [...]

12 Con algunas modificaciones. En la cita original Lévi-Strauss habla en primera persona: "[...] donde la música se vive en mí y me escucho a través de ella. El mito y la obra musical aparecen así como directores de orquesta cuyos oyentes son los silenciosos ejecutantes" (1996, 26). convirtiéndonos en silenciosos ejecutantes" $(26)^{12}$.

Peter Sloterdijk, al igual que Levi-Strauss, aunque pertenece a una formación disciplinar diferente y se vale de otro procedimiento, ha mostrado que el fenómeno de la audición ocurre en el sí del oyente y no en el instrumento. Pero a diferencia de Lévi-Strauss, Sloterdijk ha implicado la audición en el conocer, sin separarla como otra más de nuestras facultades intelectuales, tal y como - salvadas las diferencias - hemos visto ocurre en el islam espiritual. Luego de seguir paso a paso el intento de Descartes de "construir una ciencia sin oído” (Sloterdijk 1998, 302), Sloterdijk concluye que:

El cógito sonoro es justo lo contrario de lo que Descartes reclama del cógito lógico; ni es fundamento - porque no soporta nada- ni algo inconcluso porque no puede ser fijado [...]. Quien escucha las voces en el pensamiento está continuamente sumido en una esfera estremecida por otro. El pensamiento está en el sujeto como el sonido en el violín: en virtud de una relación de vibración. Los hombres son, en tanto piensan, como instrumentos de música para representaciones que significan el mundo [...]. La misma música está siempre solo en el escucharse del "instrumento", es decir, del sujeto, en cuanto uno se entiende ahora como medio sensible al sonido. (Sloterdijk 1998, 302-303) [Énfasis agregado]

Esta cita de Sloterdijk sintetiza en detalle las tres relaciones aquí analizadas con profusión. La primera: todo lo que los profesores de ney pueden llegar a escuchar de sí mismos a partir de este uso particular de su instrumento está implicado en ese conjunto de alusiones espirituales recibidas por el profeta Muhammad, sumo prototipo en el islam del ser humano estremecido por el otro de la diferencia ontológica: Allah. Este estremecimiento encuentra en la audición el móvil más eficaz de la Revelación Coránica: la escucha de una palabra anunciada por el ángel Gabriel, guardada y recibida por el Profeta Iletrado. Una escucha a la vez sinónimo y matriz cultural de la relación íntima, la confianza, la 


\begin{tabular}{r|r}
$\begin{array}{r}\text { Revista Colombiana } \\
\text { de Antropología }\end{array}$ & I3I \\
\hline Volumen 48 (2), julio-diciembre 2012 &
\end{tabular}

fidelidad y la lealtad indispensables para la recepción de secretos de ésta índole. Una escucha sinónimo de reciprocidad llevada a asuntos sagrados, en la que el devolver implica necesariamente comprender el sentido de lo recibido, despojado ya de toda literalidad y sonoridad inicial.

Esta reciprocidad hace manifiesto que en el islam todo aquello relacionado con la experiencia mística no se agota en, ni puede circunscribirse únicamente al trance ${ }^{13}$. Para estos profesores, el hecho de enseñar y cultivar en sus estudiantes una escucha de este tipo implica reinscribirse en la línea de descendencia, estrechar lazos con el ser y las cualidades del

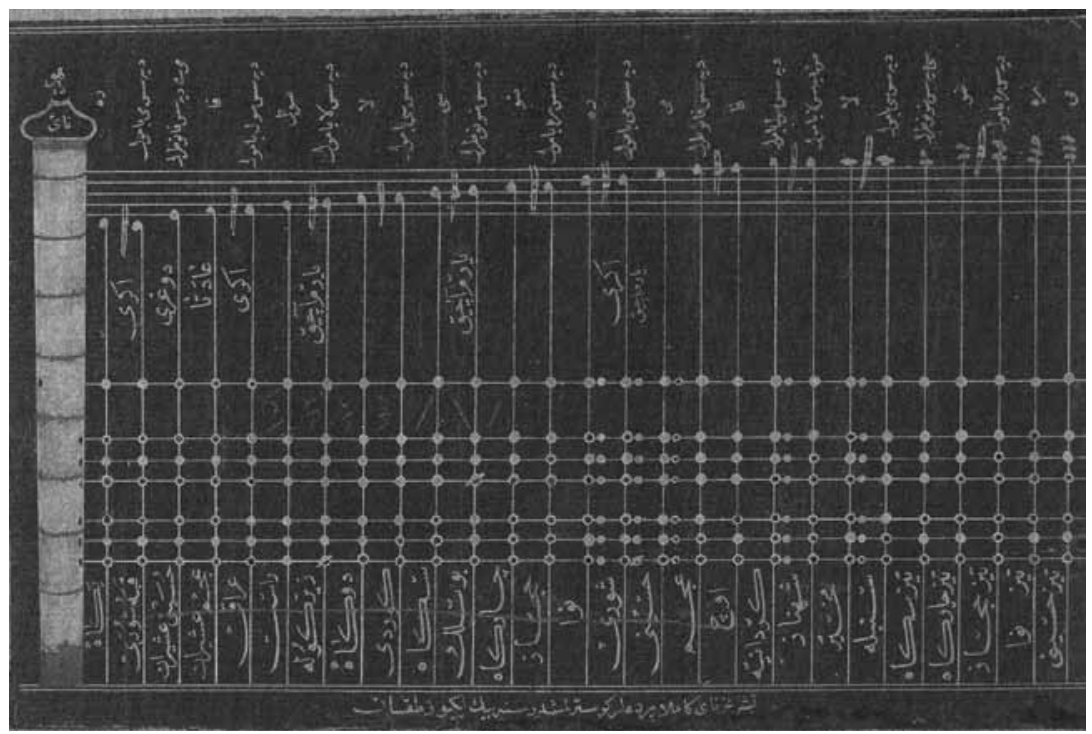

FOtO 1. TABLA DE LOS SONIDOS PRODUCIDOS POR LA FLAUTA NEY, ELABORADA EN $1873^{14}$

Fuente: Erguner $(2012,116)$.
13 Existen términos en la mística musulmana que designan las modalidades en las cuales puede presentarse ese tipo de experiencia de intimidad con Dios: el arrobamiento (sukr) y la sobriedad (sahw) (Bakhtiar 1976, 95).

14 Obra del calígrafo otomano Hasan Riza publicada por Süleyman Erguner en la segunda edición de su método de ney (Erguner 2002, 1 16). En la imagen puede apreciarse escrita la palabra árabe HU -Él, que se refiere a Dioscomo aquello que está por fuera de la flauta y como aquello que al pasar por el intérprete en forma de aliento generará posteriormente todos los sonidos que el instrumento puede producir. Esta imagen nos ilustra sobre el conjunto de representaciones y su ordenamiento jerárquico y relacional entre la fuente del sonido y sus formas posibles, el instrumento y el intérprete necesario para darle vida y existencia efectiva a esta forma de discurso divino en la música y la mística musulmanas. 
Ejercitar el kamish. Etnografías acústicas del islam y desafíos de lo sonoro en la construcción de subjetividades

Profeta mismo, para garantizar la efectividad y la continuidad de este discurso divino a través de la práctica musical. Parecerse, estar muy cerca, intimar con dichas cualidades, conservarlas y hacer de ellas el propio rostro son los ejes orientadores del tipo de experiencia mística vivida, cultivada y prodigada por estas personas (Bakhtiar 1976, 26).

La segunda relación que hace de esta práctica musical un método de subjetivación sonora es que hay algunos objetos que obtienen su máxima finalidad sonora — su carácter sagradocuando llegan, gracias a sus intérpretes, a ser paradójicamente despojados de su cualidad intrínseca: su sonido. Los instrumentos en sí mismos no suenan, y la caña vacía, el ney, ejemplifica en la mística musulmana al ser humano en disposición perfecta para

15 "De amniótico (líquido intrauterino rodeado por la membrana o amnios), aisthetos (visible, sensible y ethos (carácter moral)). Este neologismo, introducido por nosotros, se aplica a todas aquellas interacciones humanas basadas en la sugestión, la fascinación mutua, la empatía y cualquier otra modalidad de magnetismo recíproco. Como resultado de esa interacción resultan inseparables tres dimensiones: las dimensiones cálidas y envolventes que configuran un cielo protector y benévolo; las dimensiones estéticas relacionadas con la puesta en escena; y aquellas otras dimensiones de orden ético ligado a valores morales" (Castro, Castro y Castro 2008: 304). Esas tres dimensiones en este texto son: 1) la relación entre profesores y estudiantes de flauta, 2) la música sufí de Turquía, y 3) la espiritualidad musulmana. recibir el aliento vital que pasa por él sin llegar por eso a retenerlo ni adueñárselo. Y la tercera relación es que cuando reparamos en este método de subjetivación sonora capaz de agitar el líquido amnioestético (Castro, Castro y Castro 2008, 304) ${ }^{15} \mathrm{de}$ la luz del Corán y movilizar en sus participantes una evolución espiritual, nos damos cuenta de que su objetivo es producir un oyente ideal que se entregue a su práctica musical como signo del Otro Buscado, del Ser Amado

Anhelado, del Sentido Oculto Interrogado. Un tipo de oyente e intérprete que viva su subjetividad como un ejercicio constante de entrega, sabiendo, confiando y esperando que su escucha en singular llegue a emular la audición completa del Profeta: una escucha singular y poseedora del poder de reconocer el mismo sentido en variadas acepciones, capaz de identificar los secretos y misterios de la Hermandad de la Sinceridad confiados a su yerno Alí, a partir de la experiencia sonora de lo otro. Y finalmente, un tipo de subjetividad poseedora de una escucha en la que vuelven de regreso todos los sonidos, audibles e inaudibles, suscitados alguna vez en el escucharse a Sí Mismo del profeta Muhammad. 
Volumen 48 (2), julio-diciembre 2012

\title{
Kamish: mediador entre Allah y el ser humano
}

\begin{abstract}
El sonido de la madera recuerda a Allah. Yo no produzco el sonido, el sonido está siempre allí, solo podemos escucharlo gracias a estas herramientas. Los Insan-i Kamil, los Hombres Completos comprenden eso: Allah. Y ellos entienden esa realidad. Debido a esto, la historia graba sus nombres. Pero hoy en día, ese punto no es entendido por nuestros artistas y por eso su arte no es estable, solo temporal. Nosotros no entendemos esto, debido a que el tiempo está cambiando constantemente. Pero de todas formas tratamos de entenderlo y enseñarlo a los demás. Nuestra música tiene una forma diferente. Tratamos de protegerla con nuestras voces, con nuestros instrumentos. Esta forma de nuestro arte es muy importante. Si no alcanzamos esta forma, el sonido de nuestros instrumentos no será nada, el sonido del ney no será nada, no dirá nada. Pero si lo alcanzamos, entonces, eso será ney.
\end{abstract}

Entrevista con Ahmed Shajín. Fragmento de diario de campo.

 l ejercicio del kamish es una de las actividades de la espiritualidad musulmana con el poder de situar a sus practicantes en el proyecto de la Revelación Coránica. Todas esas relaciones que se desprenden de este kamish, anteriormente presentadas, son coordenadas que sitúan la subjetividad de los intérpretes ante lo más fundamental de su ser. Estas relaciones les informan de sí y son capaces de nombrar las modalidades en que su vida adquiere sentido frente a lo divino. Todo esto sin olvidarse de lo humano, ni de las prácticas, contextos y discursos culturales bien definidos perpetuados por maestros y estudiantes en su interacción.

"Y con el uso del cálamo, le enseñó al hombre lo que no sabía" (Corán, Sura A’laq. 4,5). Analizar este versículo implica recordar que los niveles del significado del Corán no se agotan en las "relaciones sintagmáticas y sintácticas del discurso" (Saussure 1974, 147), ni se agota en los "principios que opera el análisis crítico del discurso" identificados por Van Dijk, en los que interactúan hablantes, contextos y discursos en sus luchas por ser enunciados (Van Dijk 2000, 58-61). Al contrario: los niveles del significado del Corán, en el contexto aquí citado, se extienden en esa región del significado abandonada por los gramáticos de la "época clásica” (Foucault 1968, 50). Aquella región del significado en la que cada letra tiene una existencia que le viene dada no de 
Ejercitar el kamish. Etnografías acústicas del islam y desafíos de lo sonoro en la construcción de subjetividades

su funcionamiento sintáctico, sino de su "esencia divina desde la cual descendió como individualidad pura” (Borsi 1996, 6). Escuchemos a Rajab Borsi: "Los significados de las letras están en la inteligencia; sus modalidades están en el espíritu, sus formas

16 Esta semiología del lenguaje se conoce en los países musulmanes como llim-i-Abjad. Como lo señaló Michel Foucault cuando analizaba las epistemes y su relación con la gramática en las modalidades del saber en cada época, estas otras formas de la gramática basaban sus fundamentos en rasgos que él también denominó como esotéricos y místicos, prontamente abandonados por los reformadores del lenguaje de la Port Royal (Foucault 2000, 45-67). plásticas están en el alma, sus impresiones están en el corazón, su fuerza enunciativa está en la lengua y su secreto configurado en la audición” $(1996,42)^{16}$.

En este contexto, inteligencia, espíritu, alma, corazón, lengua y audición hacen referencia a una tradición gnoseológica particular acompañada de sus órganos perceptivos. Fuerza enunciativa y secreto hacen referencia a niveles objetivos o campos semánticos que interpelan estos conceptos, luego de ser trazados con el kamish-ney o con el kamish-cálamo. Así pues, mi referencia al kamish no se agota en la importancia simbólica concedida por la orden Mevleví, hoy llamada cultura Mevleví (Kücük 2003, 411). Mi referencia identifica las prácticas y los discursos que constituyen procesos de construcción de subjetividades. Prácticas y discursos que hacen del kamish objeto y agente del conocimiento divino por excelencia en esta interpretación de la Revelación Coránica, relacionada con el uso, apropiación y transformación de elementos vegetales de la naturaleza, el ejercicio de la corporalidad y la escucha en su experiencia espiritual de lo sonoro.

Esto podría resultarnos algo novedoso o incluso de aparición reciente, debido a que habitualmente se considera al islam —en el mejor de los casos - como una religión urbana en tanto separada de la naturaleza, gracias al énfasis arquitectónico desarrollado en su proyecto de sociedad ideal monumental. Esta noción ha servido para idear un tipo de religión abstracta e independiente de cualquier tipo de desarrollo figurativo o asociativo de la divinidad con otros elementos de la naturaleza en el nivel más estándar de estas acepciones (Puerta 1997, 20-29). Este hábito de pensamiento, junto con el otro que representa al islam como producto de una sociedad desértica, arenosa y sofocada, han servido para invisibilizar y callar las formas como este $-\mathrm{y}$ su pensamiento estético en particular- ha desarrollado sus representaciones, discursos e interacciones en la naturaleza. Formas de 
articulación entre estética, espiritualidad y subjetividad, gracias a la concepción musulmana de la divinidad como generadora de síntesis y unicidades articuladas, en las que el mundo vegetal, animal, humano y divino se encuentran.

De este modo, relacionar el versículo coránico con la tradición sufí anteriormente citada enfatiza la comprensión de la práctica del ney y el arte de la caligrafía árabe como tradiciones estéticas musulmanas. Tradiciones emparentadas por ser ambas garantes de la enseñanza de lo divino en sus múltiples dimensiones a partir de largos procesos de subjetivación, encargadas a su vez de producir los autores de las obras artísticas. Además de estar emparentado de manera ética y estética con la Revelación Coránica, el arte de la caligrafía también alcanzó sus máximos estándares de profesionalización gracias a instituciones culturales otomanas. A comienzos del siglo xviII los estilos del arte europeo sacudieron a Estambul, y ante su embate, esta tradición se aferró con pasión a sus líneas clásicas de desarrollo, gracias a no tener un homólogo en el arte europeo que hubiera podido impactar directamente sobre ella, y gracias a las decisiones asumidas por sus mejores exponentes: perseverar y conservar el pensamiento estético y las metodologías pedagógicas cultivadas durante siglos, y dirigir a los jóvenes estudiantes a buscar y experimentar nuevas formas de encontrar la expresión de sus sentimientos místicos en nuevas trayectorias, sin secar las fuentes que nutrieron y elevaron sus estándares por más de seis siglos (Bilgi 2004, 47).

Estas dos tradiciones estéticas encargadas de enseñar al hombre lo ignorado - tal y como se lee en el Corán- se sitúan en una didáctica de lo Oral Revelado que las hace reverberar en dos espacios singulares: el hablar y el cantar ${ }^{17}$. Victor Zuckerkandl ha analizado estos dos tipos de espacio, y ha planteado que "hay una diferencia fundamental en las relaciones que el hombre, en cuanto hablante, mantiene con los hombres, las cosas y el mundo y que las mantiene en cuanto hombre que canta. El hablante se halla siempre frente al mundo y en-frentado a él; en cuanto canta, se encuentra el hombre con-cernido por el mundo e implicado en él" $(1997,188)$. Esto nos permite comprender que la didáctica de lo Oral Revelado en

17 Cuando hablo de lo Oral Revelado me refiero a la característica del objeto de la Revelación Coránica, al carácter oral del mensaje recibido del profeta Muhammad por boca del ángel Gabriel. Como ocurre en otros pasajes en que este mismo ángel se relaciona con otros individuos de las comunidades del Libro (la Virgen María, Abraham, Moisés, Jesús, etc.) es característico que la Palabra dada por Dios aparezca en primera instancia como una manifestación oral sonora. 
Ejercitar el kamish. Etnografías acústicas del islam y desafíos de lo sonoro en la construcción de subjetividades

el arte de la caligrafía sitúa a sus practicantes y a sus posteriores espectadores en un espacio donde comparten una "relación de enfrentamiento hacia una sola dirección" (184): el uno al frente del otro, o los dos frente a la obra caligráfica. En tanto que la práctica del ney los sitúa en un espacio donde la didáctica les hace experimentar "la conjunción de quienes cantan mirando hacia la misma dirección: donde se reúne sonido y palabra, diluyendo su enfrentamiento" (184). La flauta ney, a diferencia del cálamo, no escribe las palabras del Corán en tanto emanaciones de lo Oral Revelado al profeta Muhammad por el Ángel, sino que canta el padecimiento, el develamiento y la experiencia de los secretos y misterios de la Hermandad de la Sinceridad —el secreto del Corán - en tanto emanaciones de lo Oral Recitado/ Escuchado por el profeta Muhammad, tal y como vuelve a decir la tradición sufí anteriormente analizada.

Sabemos de antemano que el ney es un instrumento usado para producir notas musicales, como lo hace el cálamo con las líneas de las letras árabes; sin embargo, lo que aquí se identifica es que ambos comparten espíritu por nacer del mismo material y en tanto generan la articulación de los modos de conocimiento pertenecientes al ámbito de la música y la caligrafía. Comparten corazón en tanto generan impresiones y motivaciones que en la mayoría de los casos garantizan la fidelidad de los estudiantes y su permanencia en las relaciones de enseñanza junto a sus maestros. Y comparten secreto en tanto generan audiciones, el Corán recitado y el anhelo del reencuentro con Allah. Ney y cálamo, por compartir la materialidad de la cual están formados, heredan un propósito que les da fin a ambos luego de haber sido producidos: enseñar al hombre lo que de Dios no sabe, conducirlo por un itinerario hacia la cercanía divina y revelarle su verdadero rostro, su verdadera dimensión humana.

Para concluir, se trató desde la etnografía la relación entre métodos de disciplinación sonora y arte caligráfico, para identificar las prácticas epistémicas sedimentadas en la historia del pensamiento musical y estético vigente en Turquía y presentar el sentido y la relevancia de estos métodos en la producción de subjetividad en el interior del islam. Una subjetividad de cara a lo sagrado, sagrada no por sí misma, sino por ser la responsable de traer hacia adelante lo que estas prácticas producen: las prácticas estéticas de la espiritualidad musulmana y la configuración de un tipo de subjetividad capaz de reconocerlas, desarrollarlas 
y vivirlas luego de que ha sido producida por dispositivos de la Revelación Coránica. Para poder concretar todo esto, siempre se han necesitado personas singulares capaces de comprenderlo y enseñarlo a otros. De lo contrario, como bien anotaba Ahmed Shajín, el sonido y el trazo de los instrumentos no será nada, ni ninguno de ellos dirá nada. Pero si se logra, entonces seguirá en marcha esa didáctica divina de lo ignorado, integrando cultura, estética y religión, situando en el seno de tal proyecto milenario a sus devotos practicantes.

\section{ReFERENCIAS}

An-Nawawi, Abu ZaKariya. 2006. "Los Cuarenta Hadices, traducidos por Isa García”. Recuperado el 24 de junio de 2012, http://viveislam. islammessage.com/file.axd?file $=2009 \% 2 \mathrm{~F} 12 \% 2 \mathrm{Flos}+$ Cuarenta + Hadices.pdf

BAKHTIAR, LALEH. 1976. Le soufisme, expressions de la quête mystique. París: Éditions du Seuil.

Bilgi, Hülya. 2004. Gönulden Bir Tuktu, Sevgi Gönül Hat Koleksiyonu / A Heartfelt Passion, The Sevgi Gönül Calligraphy Collection. Estambul: Sadberk Hanim Müzesi.

Borsi, RajAB. 1996. Les Orients des lumières. París: Verdier.

Bourdieu, PIERRE. 1990. “¿Y quién creó a los creadores?”. En Sociología y cultura, 229-230. México D. F.: Grijalbo.

Castellanos, Diego Giovanni. 2010. Islam en Bogotá: presencia inicial y diversidad. Bogotá: Universidad del Rosario.

Castro Nogueira, Laureano, Luis Castro Nogueira y Miguel Ángel CasTRO NogUEIRA. 2008. ¿Quién le teme a la naturaleza humana? Homo saudens y el bienestar en la cultura: biología evolutiva, metafísica y ciencias sociales. Madrid: Tecnos.

Corbin, Henry. 1996. Cuerpo espiritual y tierra celeste. Barcelona: Siruela.

Corbin, Henry. 2005. El imam oculto. Madrid: Losada.

During, JEAn. 1996. "Música y ritos: el sama”. En Las cofradías musulmanas desde sus orígenes hasta la actualidad, editado por Alexandre Popovic y Guilles Veins, 197-215. París: Fayard.

EFLÂKI, SHEMSu-D-Din. 1976. Leyendas de los sufíes: historias de la vida y enseñanzas de Rumi. Madrid: Edaf. 
Ejercitar el kamish. Etnografías acústicas del islam y desafíos de lo sonoro en la construcción de subjetividades

ERguner, Süleyman. 2002. Ney “Metod”. Estambul: Erguner Muzik.

Foucault, Michel. 1968. Las palabras y las cosas. Buenos Aires: Siglo XXI.

Foucault, Michel. 1978. Dits et écrits. París: Gallimard.

Foucault, Michel. 1990. Las tecnologías del yo y otros textos afines. Barcelona: Paidós Ibérica.

JÁUREguI, Jesús. 1997. "El concepto de plegaria musical y dancística”. Alteridades 9 (13): 69-82.

KüÇÜK, SEzAI. 2003. Mevlevîliğin Son yüzyili. Estambul: Simurg.

LÉvi-Strauss, Claude. 1996. Mitológicas I. Lo crudo y lo cocido. México D. F.: Fondo de Cultura Económica.

LÉvi-Strauss, Claude. 2000. El hombre desnudo. México D. F.: Siglo XXI. Lings, Martin. 1981. ¿Qué es el sufismo? Madrid: Taurus.

Mauss, MArCEL. 1970. Lo sagrado y lo profano: Obras I. Barcelona: Barral.

Moreno, Jairo. 2004. Musical Representations, Subject, Objects. The Construction of Musical Thought in Zarlino, Descartes, Rameau, and Weber. Bloomington: Indiana University Press.

Puerta Vílches, José Miguel. 1997. Historia del pensamiento estético árabe: Al-Ándalus y la estética árabe clásica. Madrid: Akal.

Redhouse, James W. 1881. The Mesnevi of Mevlana Yelaluddin Muhammed Er-Rumi. Londres: Trübner.

SAID, EDWARD. 2002. Orientalismo. Madrid: Debate.

Saussure, Ferdinand DE. 1945. Curso de lingüística general. Buenos Aires: Losada.

Shehadi, FAdLou. 1995. Philosophies of Music in Medieval Islam. Leiden: E. J. Brill.

Sloterdjik, Peter. 1998. Extrañamiento del mundo. Madrid: Pre-Textos.

VAn Dijk, Teun. 2000. “El estudio del discurso”. En El discurso como estructura y proceso, compilado por Teun Van Dijk, 58-61. Barcelona: Gedisa.

ZuCKERKANDL, Víctor. 1997. "Cantar y hablar”. En Los dioses ocultos. Círculo Eranos II, editado por Erich Neumann et ál. 171-208. Barcelona: Anthropos. 